
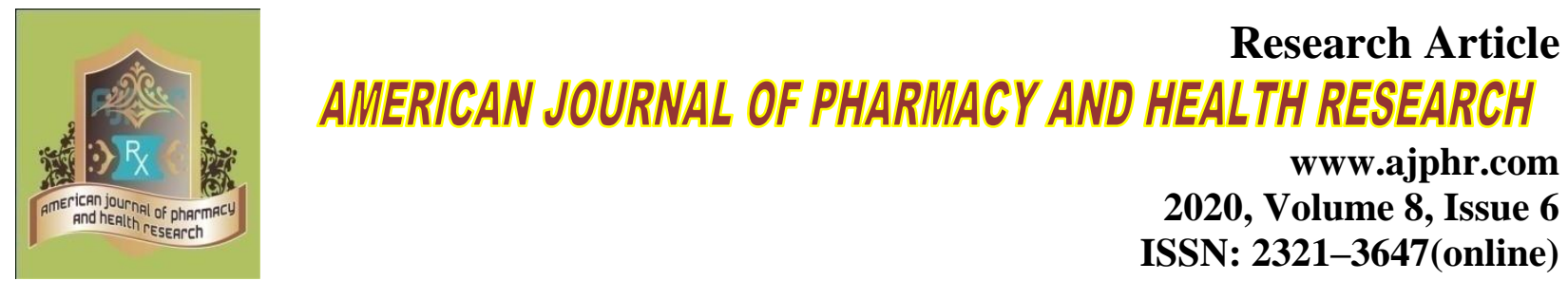

www.ajphr.com

2020, Volume 8, Issue 6

ISSN: 2321-3647(online)

\title{
Design Development and Evaluation of Perphenazine Solid Lipid Nanoparticles
}

\section{Lakshith Raj P.M., Bhagawati S.T.*, Manjunath K., Siddesh H.M., Naveen Balaji T.S.B. Sree Siddaganga college of pharmacy, B H road, Tumkur-572102}

\section{ABSTRACT}

The main aim of the study was to design Perphenazine solid lipid nanoparticles and to evaluate them. The Perphenazine solid lipid nanoparticles were prepared by the hot homogenization followed by ultrasonication method by using the different lipids (Tristearin, GMS, Compritol) Soya lecithin as stabilizer and Tween-80 used as surfactant. The FTIR test is conducted as the preliminary test, by this test there was no interaction between the drug and lipids. Then nanoparticles were evaluated for particle size, PDI, zeta potential, entrapment efficiency and invitro drug release. The particle size ranged from 53.46 to $518.6 \mathrm{~d} . \mathrm{nm}$, PDI ranged from 0.284 to 0.502 , zeta potential from -9.83 to $-40.96 \mathrm{mV}$ and entrapment efficiency was ranged from 77.45 to $95.38 \%$. The cumulative percentage release from all SLNs varied from 53.35 to $88.74 \%$ after 24hours depending upon the drug and lipid ratio and F2 formulation showed highest drug release i.e., $88.74 \%$. The release kinetic studies showed that the release first order diffusion controlled and the $n$ value (0.47) from the Korsmeyer-Peppa's model indicated the release mechanism was Quasifickian type.

Keywords: Perphenazine, Solid lipid nanoparticles, FTIR, in-vitro drug release.

*Corresponding Author Email: lakshithrajurs19@gmail.com

Received 1 June 2020, Accepted 22 June 2020

Please cite this article as: Bhagawati ST et al., Design Development and Evaluation of Perphenazine Solid Lipid Nanoparticles. American Journal of Pharmacy \& Health Research 2020. 


\section{INTRODUCTION}

Solid lipid nanoparticles (SLNs) are sub-micron colloidal carriers (50-1000 nm) which are composed of a physiological lipid, dispersed in water or in an aqueous surfactant solution. Nanoparticles made from solid lipids have attracted major attention as novel colloidal drug carriers as they have been proposed as an alternative particulate carrier system. SLNs are a nanocrystalline suspension in water, prepared from lipids, which are solid at room temperature. ${ }^{[1]}$ SLNs are composed of biodegradable and well-tolerated lipid compounds and emulsifying agents. Some of the most frequently used lipids are stearic acid, cocoa butter and cholesterol while surfactants such as soybean lecithin and sorbitan esters are used for the preparation of SLN. ${ }^{[2]}$

Perphenazine is a potent phenothiazine-type antipsychotic that is clinically used in the treatment of schizophrenia, anxiety and severe nausea or vomiting. It belongs to the first-generation neuroleptics. It shows a strong antipsychotic activity. This drug has a stronger influence on behaviour than other phenothiazines due to having in their structure piperazine group. The introduction of newer-generation antipsychotic drugs has diminished the role of Perphenazine as the mainstay therapy for psychotic disorders, Perphenazine remains a highly valuable antipsychotic drug attributed to its significantly lower costs, effective diffusion through the blood brain barrier and comparable therapeutic efficacies compared with the newer drugs. ${ }^{[3]}$ The conventional administration of Perphenazine is via the oral route, where multiple dosing is administered daily to compensate for the low oral bioavailability (30\%-50\%) of Perphenazine, which is caused by its poor aqueous solubility and first-pass hepatic metabolism. Perphenazine can be classified as a Class II drug owing to its good permeation properties through biological membranes but poor aqueous solubility. ${ }^{[4]}$ The main objective of this study develops Perphenazine solid lipid nanoparticles to enhance its bioavailability by avoiding the first pass hepatic metabolism.

\section{MATERIALS AND METHOD}

\section{Material}

Perphenazine was procured from Yarrow Chemicals, Mumbai. Tristearin was purchased from sasaol, Germany. Compritol was obtained from Gattefose, France. Glyceryl monostearate was purchased from Research lab Fine Chem Industries, Mumbai. Methanol, Tween 80 and chloroform were purchased from SD fine Chem limited, Bengaluru. Soy lecithin was obtained from HI Media laboratories Pvt ltd, Bengaluru.

\section{Preparation of solid lipid nanoparticles of Perphenazine}


SLN's were prepared by hot homogenization followed by ultrasonication method. The lipid taken as per the formula and placed in the boiling tube, then using a water bath with the suitable temperature lipid get melted. Soy lecithin and drug are added to the melted lipid. Then organic solvent mixture of chloroform and methanol in the ratio of 1:1 was added to the above mixture. Organic solvents were completely evaporated. Simultaneously another side the surfactant Tween80 was dissolved in water at same temperature of lipid phase, then slowly the aqueous phase was transferred into the lipid phase. The mixture was homogenized at 20,000 rpm for 5 minutes using high speed homogenizer, then the mixture was sonicated in the probe sonicator at $75 \%$ amplitude for 20 minutes and the temperature was maintained above $5^{\circ} \mathrm{C}$ of melting point of lipid throughout preparation. ${ }^{[5]}$

Table 1: Composition of different formulation of Perphenazine SLN's using lipid Tristearin, GMS and Compritol.

\begin{tabular}{llllllll}
\hline $\begin{array}{l}\text { Formulation } \\
\text { Code }\end{array}$ & $\begin{array}{l}\text { Drug } \\
(\mathbf{m g})\end{array}$ & $\begin{array}{l}\text { TS } \\
(\mathbf{m g})\end{array}$ & $\begin{array}{l}\text { GMS } \\
(\mathbf{m g})\end{array}$ & $\begin{array}{l}\text { CM } \\
(\mathbf{m g})\end{array}$ & $\begin{array}{l}\text { Soy } \\
(\mathbf{m g})\end{array}$ & $\begin{array}{l}\text { Tw 80 } \\
(\mathbf{m g})\end{array}$ & $\begin{array}{l}\text { Dm water } \\
(\mathbf{m l})\end{array}$ \\
\hline F1 & 10 & 50 & - & - & 25 & 25 & 10 \\
F2 & 10 & 100 & - & - & 50 & 50 & 10 \\
F3 & 10 & 150 & - & - & 75 & 75 & 10 \\
F4 & 10 & - & 50 & - & 25 & 25 & 10 \\
F5 & 10 & - & 100 & - & 50 & 50 & 10 \\
F6 & 10 & - & 150 & - & 75 & 75 & 10 \\
F7 & 10 & - & - & 50 & 25 & 25 & 10 \\
F8 & 10 & - & - & 100 & 50 & 50 & 10 \\
F9 & 10 & - & - & 150 & 75 & 75 & 10 \\
\hline
\end{tabular}

TS - Tristearin; GMS - Glyceryl Mono Stearate; CM - Compritol; Tw 80 - Tween 80; Soy - Soy lecithin; DM - Demineralized

\section{Characterization of prepared nanoparticles}

\section{Fourier-transform infrared spectroscopy (FT-IR)}

It is the primary test to check the compatibility between the pure drug and the lipids were used for the preparation solid lipid nanoparticles. FTIR was performed using shimadzu FTIR 8300 spectrophotometer, then pure drug and physical mixture of drug and lipids were scanned in the instrument from the range of $4000-500 \mathrm{~cm}^{-1}{ }^{[6]}$

\section{Particle size}

The particle size was determined by dynamic light scattering, using a Malvern system, with vertically polarized light supplied by an argon-ion laser (Cyonics) operated at 40mW. Experiments were performed at a temperature of $25.0 \pm 0.1{ }^{\circ} \mathrm{C}$ at a measuring angle of $90^{\circ}$ to the incident beam. ${ }^{[7]}$ 


\section{Zeta potential}

Zeta potential was measured using Malvern zeta sizer nanoparticles were diluted with distilled water and placed in a clear disposable zeta cell at $25^{\circ} \mathrm{C}$. The sample was subjected for two zeta runs to determine both size and potential. ${ }^{[8]}$

\section{Polydispersity index}

Polydispersity Index; a parameter calculated from a Cumulants analysis of the DLS-measured intensity autocorrelation function. Polydispersity index was determined by the same instrument i.e. Malvern zetasizer. ${ }^{[7]}$

\section{Drug Content}

About $0.2 \mathrm{ml}$ of drug loaded solid lipid nanoparticle dispersion was added into $5 \mathrm{ml}$ of methanol in centrifuge tube and vortexed for 15 minutes. Then centrifuged at $5000 \mathrm{rpm}$ for $30 \mathrm{~min}$ and supernatant was collected. Drug content in the supernatant was analysed by UV spectrophotometer for Perphenazine at $257 \mathrm{~nm}$. Drug content was calculated using following formula. ${ }^{\text {[9] }}$

$$
\text { Drug Content }=\frac{\text { Practical amount of drug obtained }}{\text { Theoritical amount of drug added }} \times 100
$$

\section{Percentage Drug Entrapment Efficiency (\%DEE)}

About $2 \mathrm{ml}$ of drug loaded SLNs was taken and placed in outer chamber of the centrisart device and the sample recovery chamber was placed on the top of sample. The unit was centrifuged at $5000 \mathrm{rpm}$ for 20 minutes. The SLNs along with encapsulated drug remains in the outer chamber and the aqueous phase was moved into the sample recovery chamber through filter membrane (molecular weight cut-off 20,000 Daltons). The resulting aqueous phase was analysed by UV spectrophotometer for Perphenazine at $257 \mathrm{~nm}$. The entrapment efficiency was calculated by using the following relationship. ${ }^{[10]}$

$\% \mathrm{DEE}=\frac{\text { Total amount of the drug }- \text { Amount of the drug in aqueous phase }}{\text { Total amount of the drug }} \times 100$

\section{In vitro drug release studies}

In vitro drug release studies were carried out in Franz diffusion cell. $2 \mathrm{ml}$ of nanoparticles dispersion was used for diffusion study. Nanoparticles containing drug were placed in donor compartment while the receiver compartment consists of $22 \mathrm{ml}$ of diffusion medium Phosphate buffer pH 7.4 maintained at $25 \pm 2{ }^{\circ} \mathrm{C}$ in Franz diffusion cell. The rpm of the magnetic bead was maintained at $50 \mathrm{rpm} .2 \mathrm{ml}$ of the aliquot was withdrawn at predetermined intervals. The samples were analyzed for the drug content by UV-Spectrophotometer at $255.8 \mathrm{~nm}$. Equal volume of the diffusion medium was replaced in the vessel after each withdrawal to maintain sink condition. 
Three trails were carried out for all formulations. From data obtained percentage drug release was calculated and plotted against function of time to study the pattern of drug release. ${ }^{[9]}$

\section{RESULTS AND DISCUSSION}

\section{Preparation of standard graph of Perphenazine using phosphate buffer at pH 7.4}

Standard solutions of Perphenazine in Phosphate buffer of $\mathrm{pH} 7.4(10-60 \mu \mathrm{g} / \mathrm{ml})$ were prepared and measured at $255.8 \mathrm{~nm}$ using UV- Spectrophotometer. The standard plot of Perphenazine was as shown in (Figure1). The obtained correlation coefficient was 0.9982 and the regression equation $\mathrm{y}=0.0166 \mathrm{x}-0.017$.

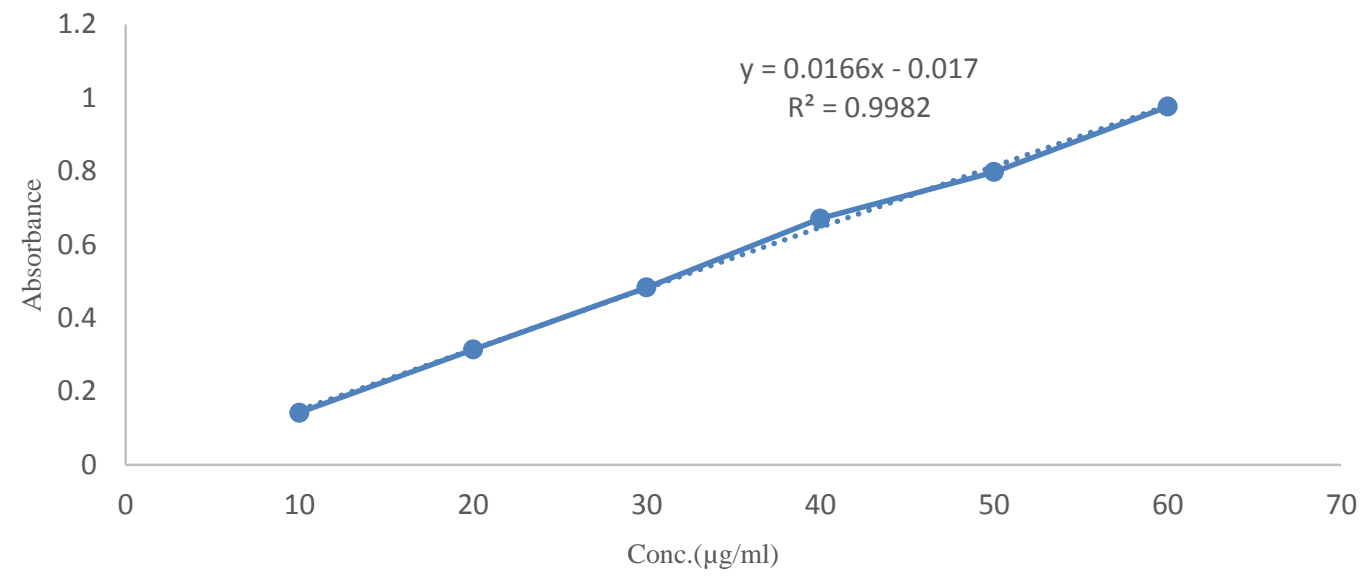

Figure 1: Standard graph of Perphenazine using phosphate buffer at pH 7.4

\section{FTIR}

The FTIR spectrum analysis was used to check the compatibility of drug with the excipients. The obtained spectra peak of the drug is matched with literature peak values were in the same range, then it confirms the drug is pure. Then spectra of drug and spectra of physical mixture of drug and excipients were matched and there is no interaction between them was proved. ${ }^{[1]}$ The peaks are shown in (Figure-2) 


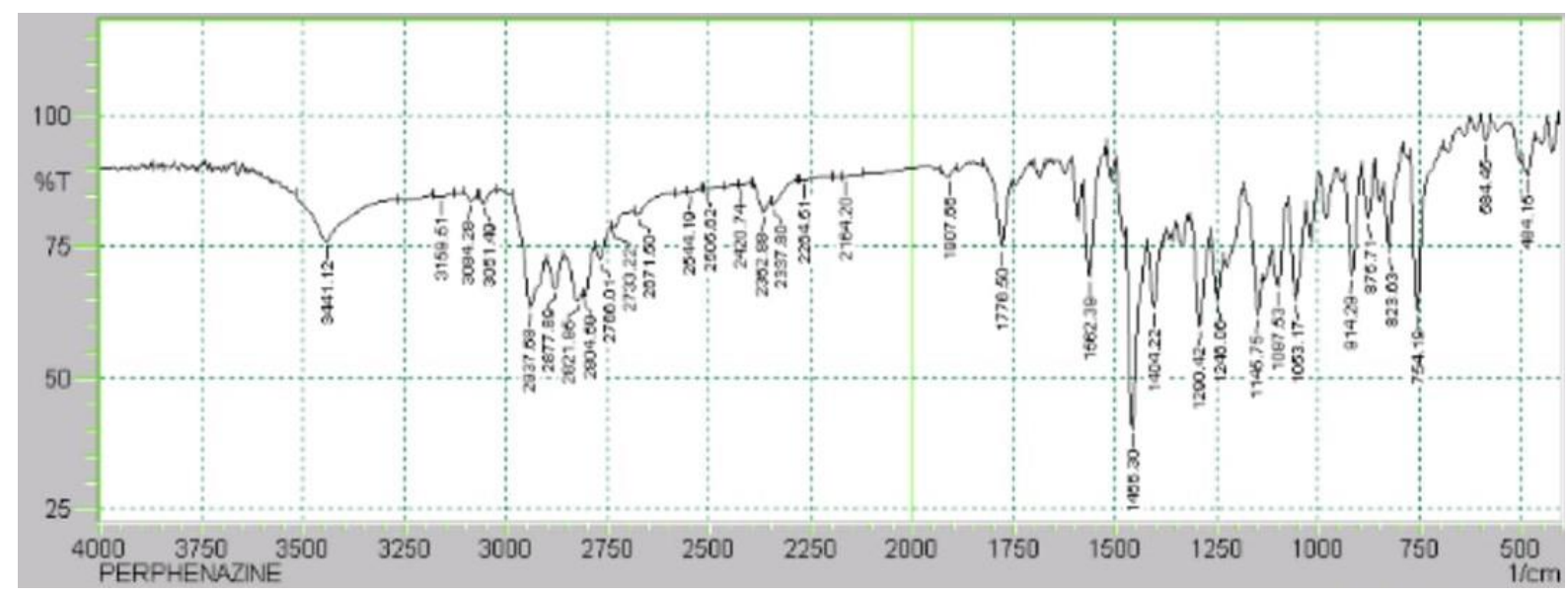

A) Perphenazine

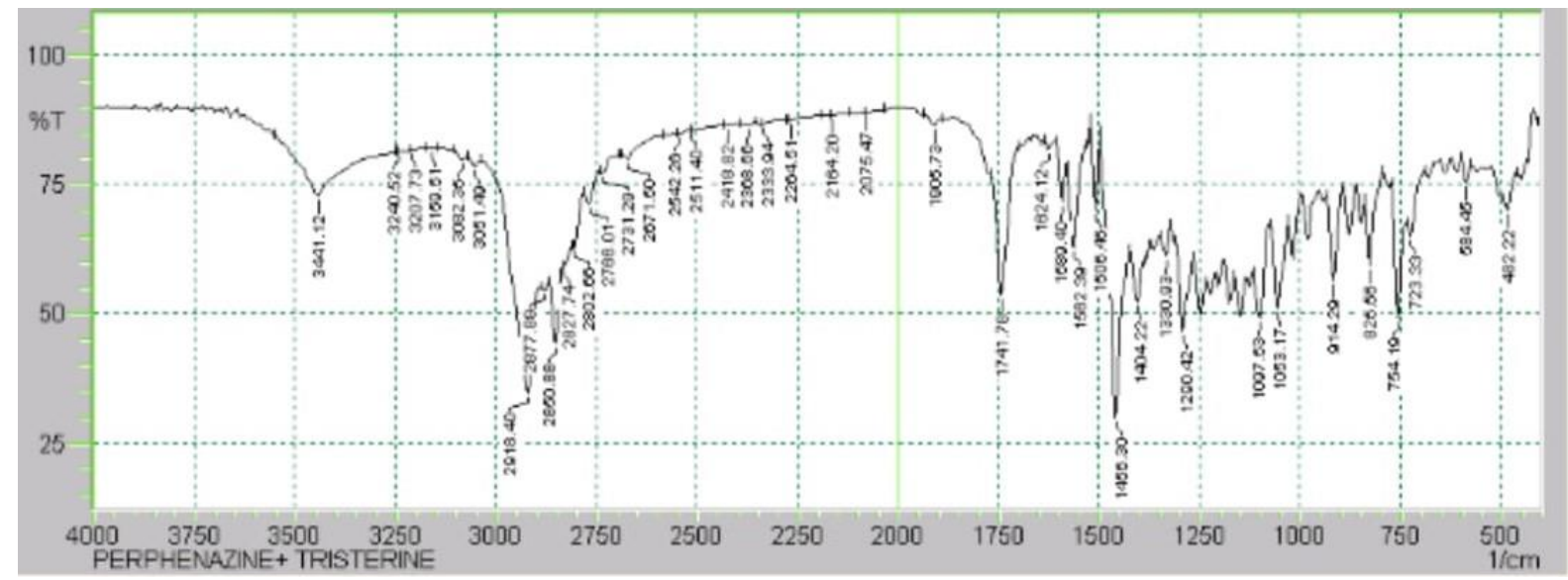

B) Perphenazine +Tristearin

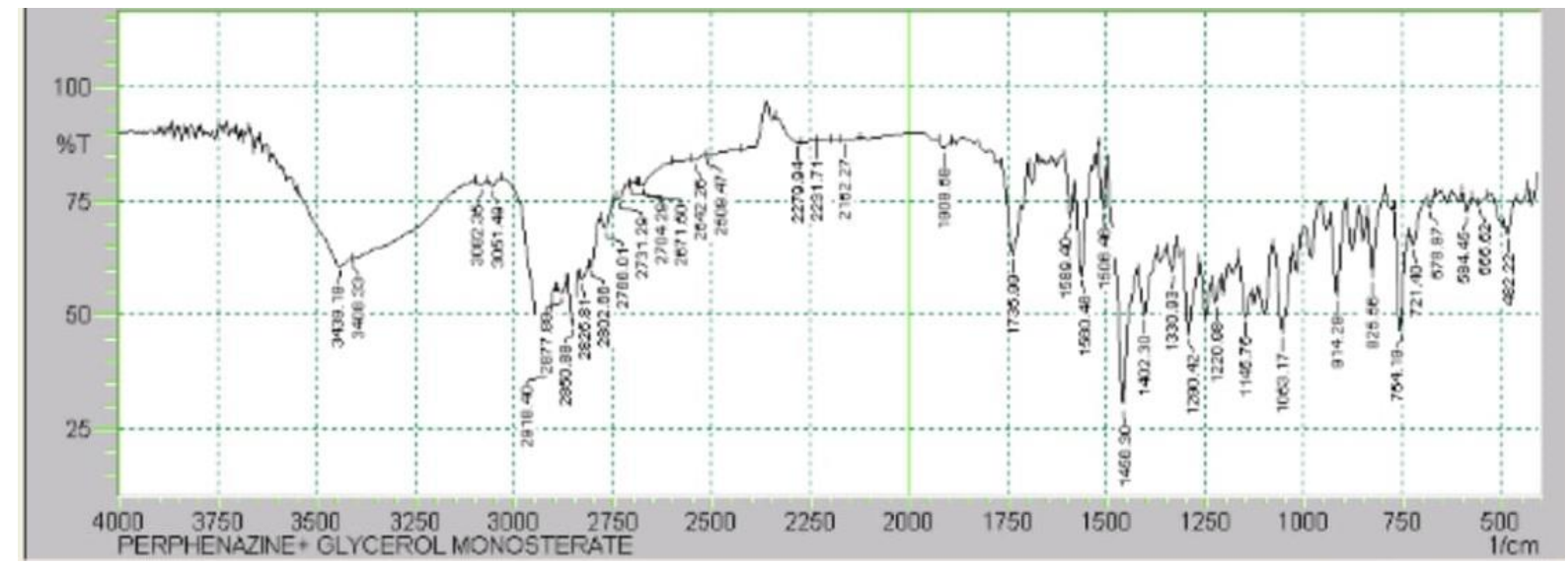

C) Perphenazine+ Glycerol monostearate 


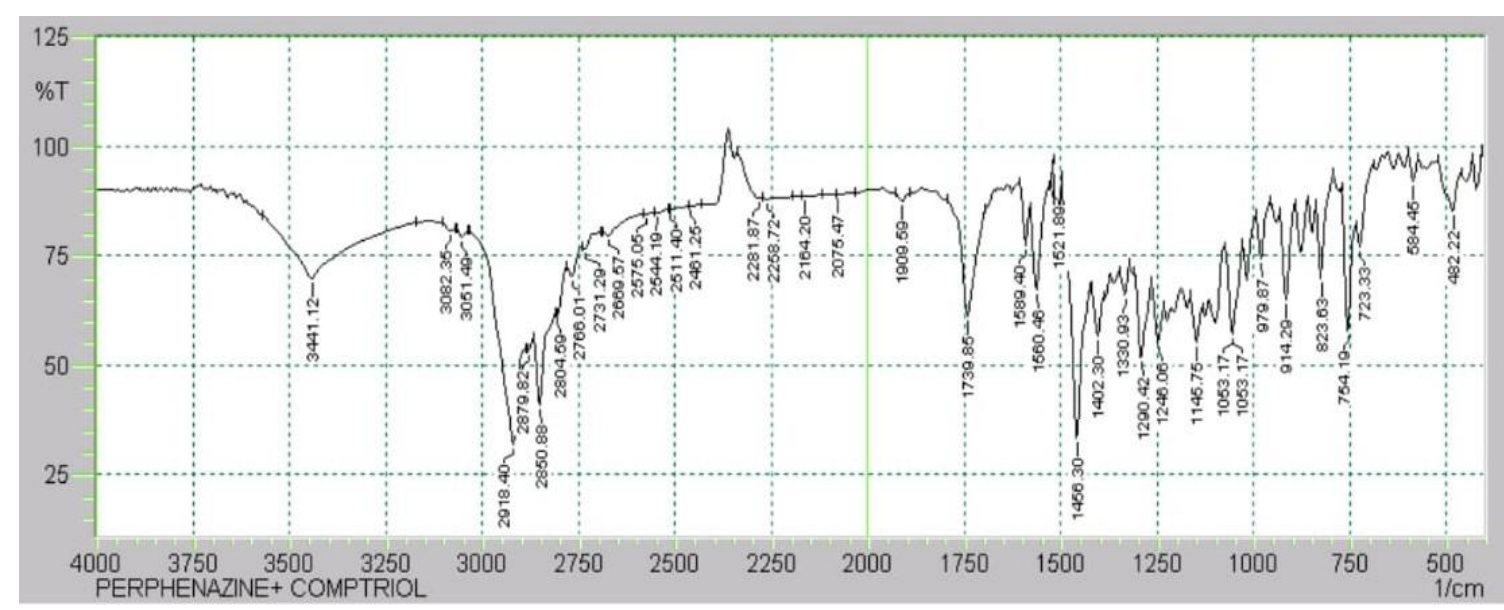

\section{D) Perphenazine+ Compritol}

Figure 2: FTIR spectra of A) Perphenazine; B) Perphenazine + Tristearin; C) Perphenazine+ Glycerol monostearate; D) Perphenazine+ Compritol.

Table 2: Functional group and their wave number by FTIR of pure drug and its physical mixtures.

\begin{tabular}{|c|c|c|c|}
\hline SI.NO & Name of the Compound & Wave number $\left(\mathrm{cm}^{-1}\right)$ & Functional group \\
\hline \multirow[t]{7}{*}{1} & Perphenazine & 3441.12 & -OH Stretching \\
\hline & & 2937.68 and 2877.89 & C-C Stretching \\
\hline & & 2821.95 and 2804.59 & C-H Stretching \\
\hline & & 1589.40and1562.39 & $\mathrm{C}=\mathrm{C}$ Aromatic Stretching \\
\hline & & 1456.30 & C-H Bending \\
\hline & & 1246.06 & C-N Stretching \\
\hline & & 754.19 & C-Cl Stretching \\
\hline \multirow[t]{7}{*}{2} & Perphenazine: Tristearin & 3441.12 & -OH Stretching \\
\hline & $(1: 1)$ & 2918.40 and 2877.89 & C-C Stretching \\
\hline & & 2827.74 and 2802.66 & C-H Stretching \\
\hline & & 1589.40and1562.39 1456.30 & $\mathrm{C}=\mathrm{C}$ Aromatic Stretching \\
\hline & & 1290.42 & C-H Bending \\
\hline & & 754.19 & C-N Stretching \\
\hline & & & C-Cl Stretching \\
\hline \multirow[t]{7}{*}{3} & Perphenazine: GMS & 3439.19 & -OH Stretching \\
\hline & $(1: 1)$ & 2918.40 and 2877.89 & C-C Stretching \\
\hline & & 2825.81 and 2802.66 & C-H Stretching \\
\hline & & 1589.40 and 1560.391456 .30 & $\mathrm{C}=\mathrm{C}$ Aromatic Stretching \\
\hline & & 1220.98 & C-H Bending \\
\hline & & 754.19 & C-N Stretching \\
\hline & & & C-Cl Stretching \\
\hline \multirow[t]{7}{*}{4} & Perphenazine: Compritol & 3441.12 & -OH Stretching \\
\hline & $(1: 1)$ & 2918.40 and 2879.82 & C-C Stretching \\
\hline & & 2850.88 and 2804.59 & C-H Stretching \\
\hline & & 1589.40 and 1560.39 & $\mathrm{C}=\mathrm{C}$ Aromatic Stretching \\
\hline & & 1456.30 & C-H Bending \\
\hline & & 1246.06 & C-N Stretching \\
\hline & & 754.19 & C-Cl Stretching \\
\hline
\end{tabular}




\section{Particle size, PDI and Zeta Potential}

Size of Perphenazine SLN's prepared with lipids (Tristearin, GMS and Compritol) using Tween 80 were in the range of 53.46to 518.6nm. PDI of all formulations were good within the range of 0.284to 0.502 . The zeta potential ranges from -9.83 to $-35.96 \mathrm{mV}$ were shown in Table 3 . Similarly, Perphenazine SLN's of optimized formulation F2 in size range of particle size 83.93 $\mathrm{nm}$ with $0.434 \mathrm{PDI}$ and $-27.9 \mathrm{mV}$ zeta potential are shown in (Figs 3 \&4). The sizes were in nano range and zeta potential obtained was optimum for good stabilization.

Size Distribution by Intensity

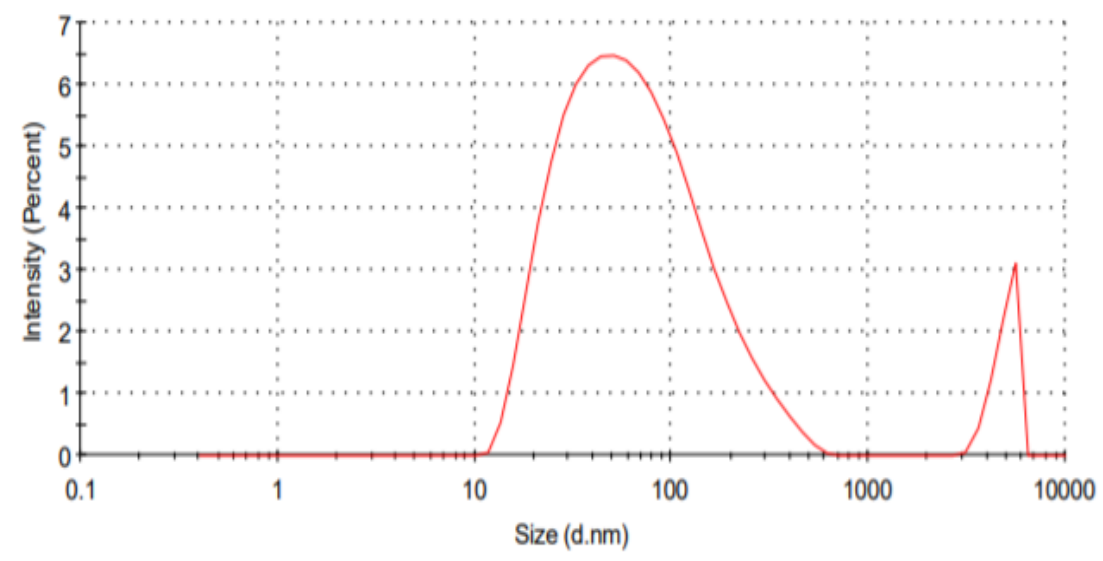

Figure 3: Size distribution of optimized formulation F2

Zeta Potential Distribution

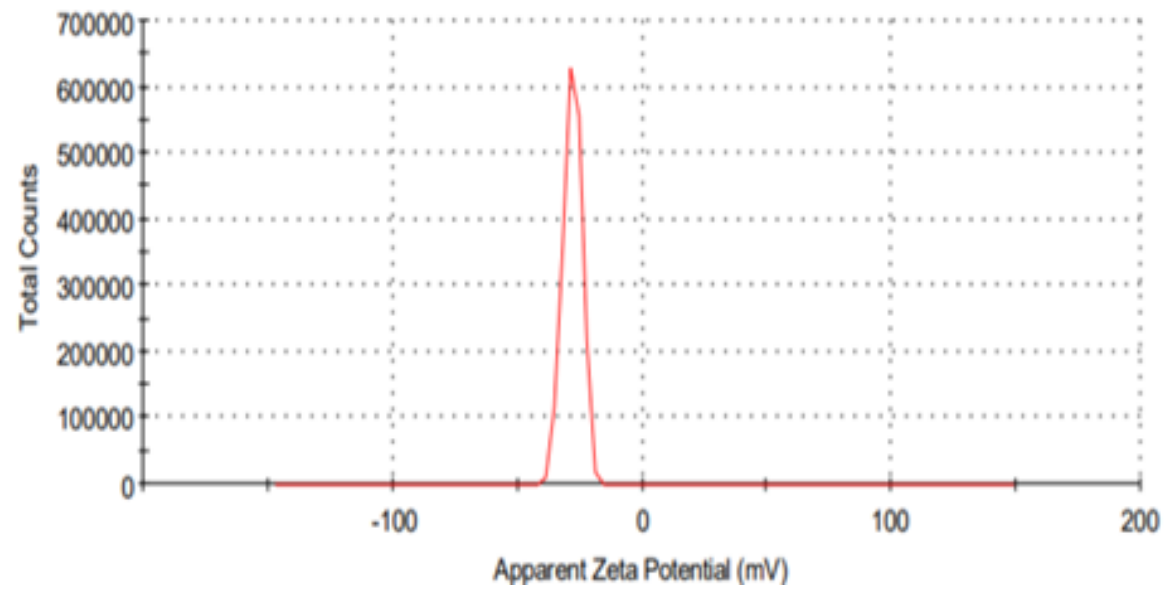

Figure 4: Zeta potential optimized formulation F2

Table 3: The Particle size, PDI and Zeta potential of Perphenazine

\begin{tabular}{llll}
\hline $\begin{array}{l}\text { Formulation } \\
\text { Code }\end{array}$ & $\begin{array}{l}\text { Particle size } \\
(\mathbf{d} . \mathbf{n m})\end{array}$ & PDI & $\begin{array}{l}\text { Zeta potential } \\
(\mathbf{m V})\end{array}$ \\
\hline F1 & 518.6 & 0.502 & -25.8 \\
F2 & 83.93 & 0.434 & -27.9 \\
F3 & 58.63 & 0.284 & -22.9 \\
F4 & 182.7 & 0.444 & -21.4 \\
\hline
\end{tabular}




\begin{tabular}{llll}
\hline F5 & 53.46 & 0.352 & -14.5 \\
F6 & 73.45 & 0.405 & -9.83 \\
F7 & 139.6 & 0.437 & -27.6 \\
F8 & 480.6 & 0.426 & -35.96 \\
F9 & 203.10 & 0.325 & -29.40 \\
\hline
\end{tabular}

\section{Drug Content and Entrapment Efficiency}

The drug content of formulations was carried out by extraction with methanol as mentioned in the methodology. The drug content is ranged from 95.54 to $99.50 \%$. The entrapment efficiency is conducted as per the method and the formulations are prepared with 150mg of lipid are showed good entrapment efficiency.

Table 4: Drug content and Entrapment Efficiency

\begin{tabular}{llllll}
\hline $\begin{array}{l}\text { Formulation } \\
\text { code }\end{array}$ & $\begin{array}{l}\text { Drug } \\
\text { content }\end{array}$ & $\begin{array}{l}\text { Amount of drug } \\
\text { in aqueous phase }\end{array}$ & $\begin{array}{l}\text { Amount of } \\
\text { drug in } \\
\text { Lipid phase }\end{array}$ & $\begin{array}{l}\text { Entrapment } \\
\text { efficiency }\end{array}$ & $\begin{array}{l}\text { Loading } \\
\text { efficiency }\end{array}$ \\
\hline F1 & 98.42 & 0.996 & 9.004 & 90.04 & 18.00 \\
F2 & 97.86 & 0.728 & 9.272 & 92.72 & 9.72 \\
F3 & 99.50 & 0.452 & 9.538 & 95.38 & 6.35 \\
F4 & 95.54 & 2.167 & 7.833 & 78.33 & 15.66 \\
F5 & 97.79 & 1.680 & 8.32 & 83.20 & 8.32 \\
F6 & 98.12 & 1.198 & 8.802 & 88.02 & 5.868 \\
F7 & 97.06 & 2.255 & 7.745 & 77.45 & 15.49 \\
F8 & 96.38 & 2.156 & 7.844 & 78.44 & 7.84 \\
F9 & 99.21 & 2.098 & 7.902 & 79.02 & 5.268 \\
\hline
\end{tabular}

In vitro release studies

The prepared formulations are subjected into the in vitro release through the Franz diffusion method for the selection of optimized formulation. The F2 formulation showed good percentage cumulative drug release $88.74 \%$ in 24 hours from rest of all the formulation, then the F2 formulation is considered as optimized formulation. The \% CDR graphs are showed in (figure 5).

Table 5: \% Cumulative drug release of all the formulation.

\begin{tabular}{lll}
\hline Formulation & \%CDR@ & $\mathbf{2 4}$ \\
\hline F1 & 79.36 & \\
F2 & 88.74 & \\
F3 & 75.31 & \\
F4 & 61.74 & \\
F5 & 67.77 & \\
F6 & 56.75 \\
F7 & 63.8 \\
F8 & 69.04 \\
F9 & 53.35 \\
\hline
\end{tabular}




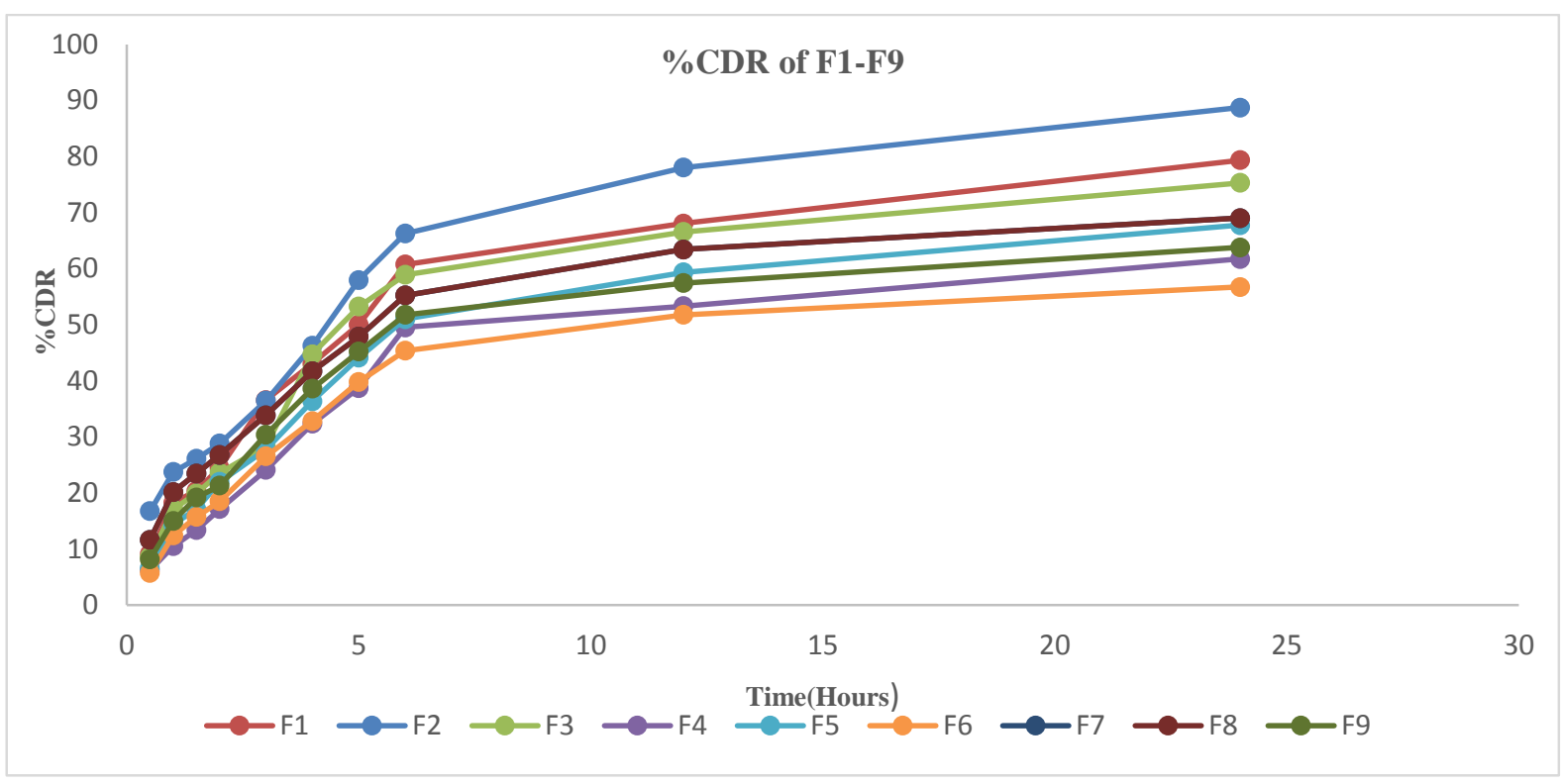

Figure 5: The in vitro release of all the formulations.

\section{Release kinetics}

The obtained data of all the formulations were fitted into various kinetic equations such as zero order, first order. Higuchi model and Peppa's model. $\mathrm{R}^{2}$ values of zero order range from 0.679 to 0.7706 and for the first order range from 0.7271 to 0.9379 and for the Higuchi model range from 0.8612 to 0.9161 .The optimised formulation F2 showed regression value of first order is greater than zero order and Higuchi model and release kinetics graph of if shown in( figure 6). Then obtained data were fitted to Korsmeyer-Peppa's model was better with higher $\mathrm{R}^{2}(0.9174$ to 0.9588 ) values, and the ' $n$ ' value obtained from the Korsmeyer-Peppa's model was 0.4732 it is less than 0.5. Hence, the mechanism of drug release from these SLN's was Quasi-Fickian diffusion mechanism.

Table 6: The regression values of kinetic models of different formulations of Perphenazine.

\begin{tabular}{llllll}
\hline $\begin{array}{l}\text { Formulation } \\
\text { Code }\end{array}$ & \multicolumn{2}{l}{ Regression Factor } & \multicolumn{2}{l}{$\begin{array}{l}\text { Korsmeyer- } \\
\text { Peppa's }\end{array}$} \\
\cline { 2 - 4 } & $\begin{array}{l}\text { Zero } \\
\text { order }\end{array}$ & $\begin{array}{l}\text { First } \\
\text { order }\end{array}$ & $\begin{array}{l}\text { Higuchi } \\
\text { model }\end{array}$ & R $^{2}$ & n \\
& 0.7374 & 0.8841 & 0.901 & 0.9393 & 0.5746 \\
F1 & 0.7706 & 0.9379 & 0.9161 & 0.9588 & 0.4732 \\
F2 & 0.6956 & 0.8249 & 0.8664 & 0.9234 & 0.5827 \\
F3 & 0.7179 & 0.8016 & 0.8816 & 0.9379 & 0.6424 \\
F4 & 0.7352 & 0.8413 & 0.9006 & 0.9343 & 0.6088 \\
F5 & 0.6852 & 0.76 & 0.8655 & 0.9174 & 0.605 \\
F6 & 0.7456 & 0.8136 & 0.9073 & 0.9264 & 0.6461 \\
F7 & 0.7059 & 0.8085 & 0.8826 & 0.9444 & 0.4766 \\
F8 & 0.679 & 0.7271 & 0.8612 & 0.9267 & 0.5544 \\
F9 & & & & & \\
\hline
\end{tabular}



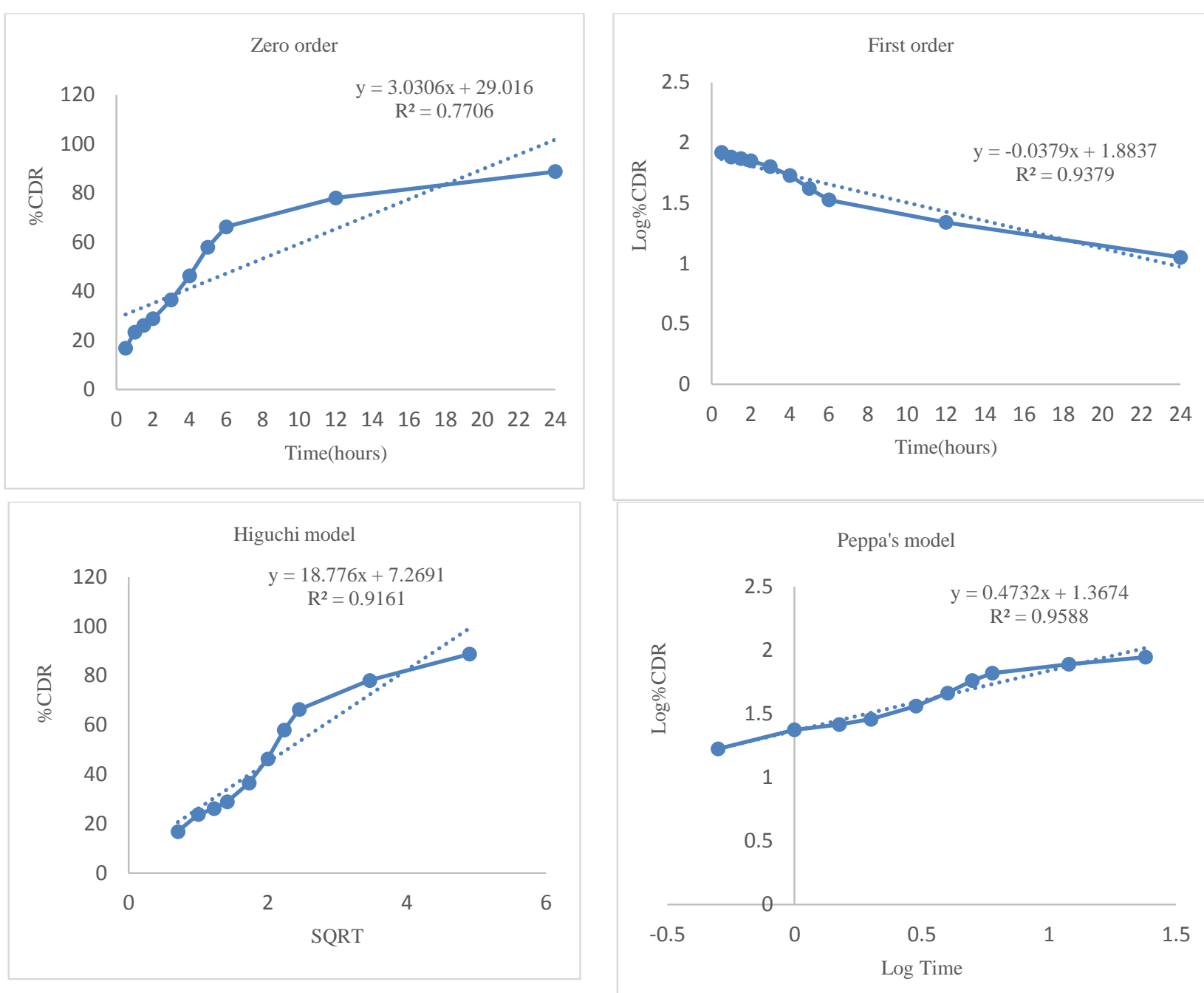

Figure 6: The release kinetic models of optimized formulation F2

\section{CONCLUSION}

The Perphenazine solid lipid nanoparticles were prepared by using different lipids like Tristearin, GMS and Compritol and Soy lecithin as stabilizer and Tween 80 as surfactant. From the FTIR study it showed that there is no interaction between the drug and used lipids. The Perphenazine solid lipid nanoparticles were prepared by hot homogenization method followed by ultrasonication method. The optimised formulation F2 prepared by $1 \% \mathrm{w} / \mathrm{v}$ of tristearin and $0.5 \% \mathrm{w} / \mathrm{v}$ of tween 80 . The release kinetic model values of this formulation follow Quasi-Fickian diffusion. Then rest of all the formulations have good size, PDI, zeta potential with good entrapment efficiency.

It can be concluded that the formulated SLNs of Perphenazine widely accepted and physiologically safe lipids was capable of exhibiting sustained release properties for a period of 24 hours also may be reduce frequency of dosing, thereby minimizing the occurrence of side effects, improve bioavailability and increase the effectiveness of the drug. 


\section{REFERENCES}

1. Sivadasan D, Madavan B, Penmatsa SD, Bathini ST. Formulation and characterization of solid lipid nanoparticles of rifampicin. Erciyes Med J. 2013;35(1):1-5.

2. Mehnert W, Mäder K. Solid lipid nanoparticles: production, characterization and applications. Adv Drug Deliv Rev 2001; 47(2-3): 165-96

3. Dong B, Hadinoto K. Amorphous nanoparticle complex of perphenazine and dextran sulfate as a new solubility enhancement strategy of antipsychotic perphenazine. Drug Dev Ind Pharm. 2017;43(6):996-1002.

4. Laitinen R, Suihko E, Bjorkqvist M, Riikonen J, Lehto V, Jarvinen K. Perphenazine solid dispersions for orally fast-disintegrating tablets: Physical stability and formulation. Drug Dev Ind Pharm. 2010; 36(5):601-13.

5. Khames A, Khaleel MA, El-Badawy MF, El-Nezhawy AO. Natamycin solid lipid nanoparticles-sustained ocular delivery system of higher corneal penetration against deep fungal keratitis: preparation and optimization. Int. J. Nanomed, 2019; 14: 2515-31

6. Nair R, Kumar AC, Priya VK, Yadav CM, Raju PY. Formulation and evaluation of chitosan solid lipid nanoparticles of carbamazepine. Lipids in health and disease, $2012 ; 11(1) ; 72$.

7. Heinz F, Simon R, Heinz K, Christof A, Matthias E. Comparison of different characterization methods for nanoparticle dispersions before and after aerosolization. Analytical methods.2014;6;7324-7336.

8. Sanjay S, Ajay KD, Achint J, Jayanth KP, Subhashis C. Formulation and evaluation of solid lipid nanoparticles of a water-soluble drug: Zidovudin. ChemPhrm. Bull. 2010; 3:650-655.

9. Gouda R, Baishya H, Qing Z. Application of mathematical models in drug release kinetics of carbidopa and levodopa ER tablets. J Dev Drugs, 2017; 6(02): 1-8.

10. Cirri M, Maestrini L, Maestrelli F, Mennini N, Mura P, Ghelardini, C et al. Design, characterization and in vivo evaluation of Nanostructured Lipid Carriers (NLC) as a new drug delivery system for hydrochlorothiazide oral administration in pediatric therapy. Drug delivery, 2018; 25(1): 1910-21 
11. Wang L, Zeng F, Zong L. Development of orally disintegrating tablets of Perphenazine/hydroxypropyl- $\beta$-cyclodextrin inclusion complex. Pharm Dev Tech. 2012:110. 